\title{
Levantamento de Práticas Agronômicas e Distribuição GEOGRÁFICA DE Bidens spp. RESISTENTES AOS HERBICIDAS INIBIDORES de Als nos Estados do Rio Grande do Sul e do Paraná ${ }^{1}$
}

\author{
Survey of Agronomic Practices and Distribution of ALS Resistant Bidens spp. in the States of Rio \\ Grande do Sul and Paraná
}

HERNANDES, G.C. ${ }^{2}$, VIDAL, R.A. ${ }^{3}$ e WINKLER, L.M. ${ }^{3}$

\begin{abstract}
RESUMO - Bidens spp., conhecidas como picão-preto, são espécies daninhas que interferem no rendimento das culturas anuais. Nos Estados do Rio Grande do Sul e Paraná, o seu controle com herbicidas inibidores da enzima acetolactato sintase (ALS) está se tornando ineficiente, sugerindo o aumento de populações resistentes a esse grupo de herbicidas. Os objetivos deste trabalho foram avaliar a distribuição geográfica de Bidens spp. resistente aos herbicidas inibidores da ALS em propriedades do Rio Grande do Sul e Paraná e determinar os principais aspectos agronômicos envolvidos na seleção dos indivíduos resistentes. Sementes de biótipos de picão-preto foram coletadas em 35 municípios desses dois Estados, em áreas onde ocorre resistência aos herbicidas mencionados. Na ocasião da coleta das sementes, entrevistaram-se os produtores quanto a manejo das plantas daninhas, sistema de preparo do solo, rotação de culturas e colheita. Os resultados evidenciam que Bidens spp. resistentes aos herbicidas inibidores de ALS estão amplamente distribuídas no Rio Grande do Sul e no Paraná. Constatou-se ausência de rotação de culturas e ampla adoção do sistema de plantio direto. O provável fator responsável pela seleção de biótipos de Bidens spp. resistentes aos herbicidas foi o elevado uso de inibidores da ALS nas áreas amostradas.
\end{abstract}

Palavras-chave: chlorimuron, picão-preto, resistência.

\begin{abstract}
Bidens spp., known as beggarticks are important weeds and reduce grain yield in several summer crops in Brazil. In the states of Rio Grande do Sul and Paraná, the control of this weed with ALS-inhibiting herbicides is becoming inefficient, suggesting an increasing weed resistance problem. The objectives of this research were to evaluate the geographic distribution of ALS-resistant Bidens spp. in the states of Rio Grande do Sul and Paraná and to determine the main agronomic causes of resistance selection. Seeds of beggarticks biotypes were sampled in 35 counties in the states of Rio Grande do Sul and Paraná, in places with suspected resistance to ALS-inhibitors. Farmers were applied questionnaires on methods of weed control, tillage system, crop rotation and harvesting operations during current and previous years. Bidens spp. resistant to ALS-inhibiting herbicides were found in all counties assessed. No crop rotation and intense use of no-tillage are predominant on the farms. The most probable cause of selection of herbicide-resistant Bidens spp. is the intensive use of ALS-inhibitors.
\end{abstract}

Key words: chlorimuron, beggarticks, resistance.

1 Recebido para publicação em 22/3/2005 e na forma revisada em 25/11/2005.

2 Eng.-Agr., M.S., Programa de Pós-Graduação em Fitotecnia da Universidade Federal do Rio Grande do Sul UFRGS); ${ }^{3}$ Eng.-Agr., Ph.D., Faculdade de Agronomia da UFRGS, Caixa Postal 776, 15.100 Porto Alegre-RS, Bolsistas do CNPq, <ribas.vidal@ufrgs.br>. 


\section{INTRODUÇÃO}

A cultura da soja é cultivada no Rio Grande do Sul desde o ano de 1961. Nos anos de 1986 a 1990, os Estados do Rio Grande do Sul e Paraná contribuíam com aproximadamente 50\% da produção do grão no país (Costa, 1996).

A soja é uma das principais culturas do Brasil e do mundo, possuindo grande valor econômico. No Brasil, no ano agrícola de 2002/ 03 , foram cultivados 18,5 milhões de hectares, com rendimento médio de $2.790 \mathrm{~kg} \mathrm{ha}^{-1}$. A produção obtida nesse mesmo ano alcançou um total de 51 milhões de toneladas, superior em $22 \%$ à safra anterior, que foi de 42 milhões de toneladas, tornando o Brasil um dos maiores exportadores do grão de soja no mundo.

O controle de plantas daninhas dicotiledôneas na cultura da soja na década de 1970 era realizado pelo herbicida metribuzin, o qual possui o mecanismo de ação de inibição do fluxo de elétrons no fotossistema II (FS II) das plantas sensiveis. Esse herbicida foi desenvolvido nas décadas de 1950 e 1960 e sua aplicação em soja é feita apenas em préemergência das plantas daninhas (Vidal \& Merotto Jr., 2001).

Na década de 1980, com o avanço da tecnologia agroquímica, foram desenvolvidas novas moléculas herbicidas com outros mecanismos de ação para controle de plantas daninhas dicotiledôneas na cultura da soja, aplicados em pós-emergência. Os herbicidas inibidores da enzima protoporfirinogênio oxidase (PROTOX) foram desenvolvidos a partir da década de 1980 para controle de dicotiledôneas na cultura da soja (Ahrens, 1994; Hess, 2000), podendo se destacar os seguintes: acifluorfen, fomesafen e lactofen, pertencentes ao grupo dos difeniléteres; flumiclorac e flumioxazin, pertencentes ao grupo das ftalamidas; e carfentrazone e sulfentrazone, pertencentes ao grupo das triazolinonas (Vidal \& Merotto Jr., 2001). A maior eficiência no controle de plantas daninhas dicotiledôneas na cultura da soja com esses herbicidas é obtida quando as plantas daninhas se encontram com duas a seis folhas (Vidal \& Merotto Jr., 2001).

Em meados da década de 1980, o controle de plantas daninhas dicotiledôneas na cultura da soja passou a ser realizado com herbicidas inibidores da enzima acetolactato sintase (ALS). Os herbicidas desse grupo são seletivos para a cultura da soja, possuindo amplo espectro de ação de espécies e baixa toxicidade em mamíferos (Devine et al., 1993; Vidal \& Merotto Jr., 2001). A época de aplicação flexivel e a elevada eficácia no controle de plantas daninhas dicotiledôneas permitiram que esses produtos se tornassem os principais herbicidas na cultura da soja.

No Brasil, a ocorrência de plantas daninhas resistentes aos herbicidas inibidores de enzima ALS foi registrada pela primeira vez em Bidens spp. (Monqueiro et al., 2000). Dentre os fatores que favorecem a seleção de biótipos resistentes, destacam-se os inerentes à planta e os agronômicos (Bourgeois \& Morrison, 1997).

A resistência aos inibidores da ALS se deve principalmente à modificação de um aminoácido na estrutura desta enzima, originada de uma mutação no gene que codifica para ela. A freqüência inicial do alelo que confere a resistência aos inibidores da ALS em Lolium rigidum é elevada e corresponde a $10^{-4}$. Especula-se que a alta freqüencia inicial do gene de resistência explica, em parte, o rápido desenvolvimento da resistência (Preston \& Powles, 2002).

O sistema de monocultura favorece o aumento do banco de sementes de algumas espécies daninhas, devido ao controle deficiente destas, decorrente das limitações dos herbicidas utilizados (Owen, 2001). O aumento no banco de sementes favoreceu o surgimento de biótipos mais adaptados às condições do ambiente, ou seja, mais competitivos por recursos com as culturas (Radosevich et al., 1997). Além disso, o aumento do banco de sementes eleva a probabilidade de seleção de biótipos resistentes a herbicidas (Vidal \& Fleck, 1997).

Por meio do desenvolvimento do sistema de semeadura direta, o controle de plantas daninhas tornou-se mais eficiente, porém dependente da utilização de herbicidas. Esse método de controle apresenta elevado risco de seleção de biótipos de plantas daninhas resistentes, em razão da dependência de um único método de controle (Brown, 1996; Owen, 2001). 
Na literatura brasileira somente foi publicado um levantamento sobre a distribuição geográfica e as causas da resistência aos herbicidas inibidores da ALS em Euphorbia heterophylla (Vidal et al., 2004). Os objetivos deste trabalho foram avaliar a distribuição geográfica de Bidens spp. resistente aos herbicidas inibidores da ALS em propriedades do Rio Grande do Sul e Paraná e determinar os principais aspectos agronômicos envolvidos na seleção dos indivíduos resistentes.

\section{MATERIAL E MÉTODOS}

\section{Coleta de sementes}

As sementes de Bidens spp. provenientes de plantas sobreviventes das aplicações de herbicidas inibidores da ALS foram coletadas em lavouras de soja entre os meses de fevereiro e abril de 2001 (Rio Grande do Sul) e 2002 (Paraná). Aproximadamente 2.000 sementes foram coletadas por local amostrado. Em cada local foram amostradas pelo menos 50 plantas, distribuídas aleatoriamente na área. As sementes foram coletadas em propriedades localizadas nos municípios de Assis Chateaubriand, Bandeirante do Oeste, Campina da Lagoa, Foz do Iguaçu, Flor do Oeste, Goioerê, Maripá, Nova Cantu, Pato Branco, Palmeira, Palotina, Quarto Centenário, Renascença, Ubiratã e Vitorino, no Paraná (Figura 1); e Almirante Tamandaré do Sul, Bela Vista, Bossoroca, Capão do Cipó, Chapada, Carazinho, Coxilha, Colorado, Coqueiros do Sul, Ernestina, Espumoso, Júlio de Castilhos, Lagoa 3 Cantos, Mato Castelhano, Passo Fundo, Palmeira das Missões, Saldanha Marinho, São Francisco de Assis, Santo Antônio das Missões e Victor Graeff, no Rio Grande do Sul (Figura 2).

A coleta ocorreu em 38 locais no Paraná e 30 no Rio Grande do Sul que apresentavam suspeita de resistência aos herbicidas inibidores da ALS. A área total amostrada representou 15.547 hectares, sendo 5.116 ha localizados no Paraná e 10.431 ha no Rio Grande do Sul.

As sementes coletadas foram catalogadas, acondicionadas em envelopes de papel e armazenadas em câmara com temperatura de $4^{\circ} \mathrm{C}$ e umidade do ar controlada. Na ocasião da coleta das sementes, os produtores responderam a um questionário semelhante ao apresentado por Vidal et al. (2004).

\section{Verificação da resistência}

No mês de junho de 2003, as sementes coletadas de Bidens spp. foram colocadas em potes plásticos (50 sementes por vaso) com volume de $300 \mathrm{~mL}$, preenchido com substrato areia:solo na proporção de 1:1. Na ocasião dessa semeadura também foram semeadas Bidens spp. sensiveis aos herbicidas inibidores da ALS oriundas de áreas da região de Porto Alegre, para servirem como testemunha.

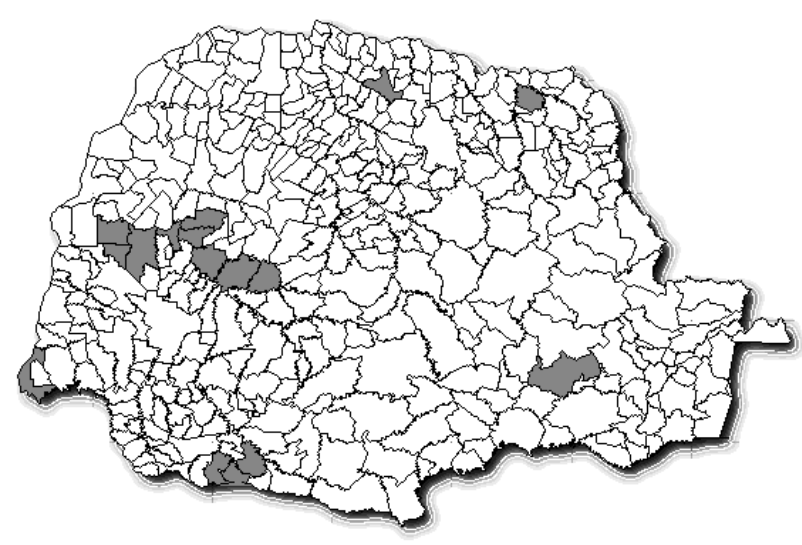

Figura 1 - Mapa do Estado do Paraná, com a localização geográfica dos municípios amostrados em cinza.

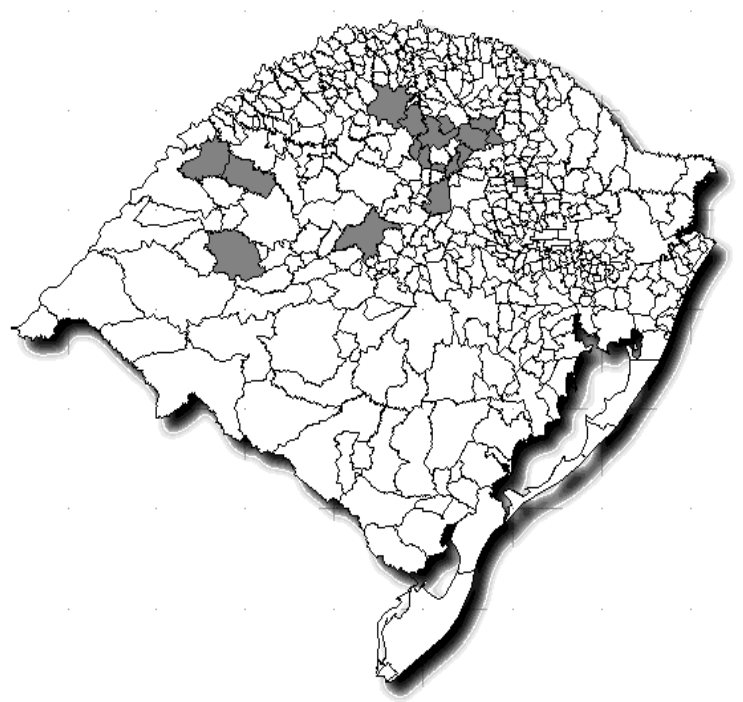

Figura 2 - Mapa do Estado do Rio Grande do Sul, com a localização geográfica dos municípios amostrados em cinza.

Planta Daninha, Viçosa-MG, v. 23, n. 4, p. 677-682, 2005 
Os vasos foram colocados em bandejas plásticas com água, para manter o solo constantemente irrigado por capilaridade. A temperatura média do ar durante a condução do experimento foi de aproximadamente $20^{\circ} \mathrm{C}$, e o período de luminosidade, de 12 horas diárias. Quando as plântulas se encontravam no estádio de desenvolvimento de quatro a seis folhas, foram aspergidas com o herbicida chlorimuron (Classic) na dose de $40 \mathrm{~g} \mathrm{ha}^{-1}$, utilizando-se pulverizador costal pressurizado com $\mathrm{CO}_{2}$, munido com quatro bicos tipo leque, com pontas $80.02 \mathrm{VS}$, com volume de calda equivalente a $220 \mathrm{~L} \mathrm{ha}^{-1}$ e pressão de trabalho de $200 \mathrm{kPa}$. A aplicação foi realizada às $16 \mathrm{~h}$ e, na ocasião da aplicação, a temperatura do ar era de $19{ }^{\circ} \mathrm{C}$, com umidade relativa do ar de $75 \%$. Os procedimentos foram repetidos por duas vezes, e os biótipos que sobreviveram aos tratamentos foram confirmados como resistentes. As avaliações foram realizadas aos 14 e 28 dias após a aspersão do herbicida.

\section{RESULTADOS E DISCUSSÃO}

Foram encontrados $50 \%$ ou mais de plantas sobreviventes - portanto, resistentes - em cada amostra coletada, ao passo que não sobreviveram plantas nos potes contendo testemunha sensivel. Isso significa que a resistência ao herbicida chlorimuron está disseminada nas regiões amostradas. Para 58\% das áreas amostradas no Estado do Paraná e 67\% das amostras no Rio Grande do Sul, os produtores já suspeitavam da resistência por dois ou mais anos (Tabela 1).

O tamanho da área com suspeita de resistência na propriedade apresentou distribuição distinta entre os Estados. Enquanto 32\% das propriedades do Paraná com resistência possuíam área inferior a 10 ha, no Rio Grande do Sul, $50 \%$ das propriedades possuíam área igual ou superior a 51 ha (Tabela 2).

Nas áreas amostradas, todas as propriedades utilizavam o sistema de semeadura direta. No Paraná e no Rio Grande do Sul, 77 e 90\% dos produtores, respectivamente, cultivavam nesse sistema de semeadura há mais de cinco anos (Tabela 3). Este sistema de semeadura eleva o risco de surgimento de biótipos resistentes devido à dependência de herbicidas como principal método de controle de plantas daninhas (Brown, 1996; Owen, 2001).
Tabela 1 - Percentual de agricultores que suspeitavam de resistência na área amostrada, de acordo com o tempo (anos)

\begin{tabular}{|c|c|c|}
\hline \multirow{2}{*}{$\begin{array}{c}\text { Tempo de suspeita } \\
\text { (anos) }\end{array}$} & \multicolumn{2}{|c|}{ Estado } \\
\cline { 2 - 3 } & PR & RS \\
\hline 1 & $42^{\frac{1}{}}$ & 33 \\
\hline$\geq 2$ & 58 & 67 \\
\hline
\end{tabular}

1/ valores representam a porcentagem de produtores em cada Estado que suspeitavam da resistência, em relação ao total de entrevistados.

Tabela 2 - Área de distribuição da resistência nos locais avaliados nos Estados do Paraná e Rio Grande do Sul

\begin{tabular}{|c|c|c|}
\hline \multirow{2}{*}{$\begin{array}{c}\text { Área com resistência } \\
\text { (ha) }\end{array}$} & \multicolumn{2}{|c|}{ Estado } \\
\cline { 2 - 3 } & $\mathrm{PR}^{\underline{2} /}$ & $\mathrm{RS}^{\underline{3}}$ \\
\hline$<10$ & 32 & 7 \\
\hline $11-20$ & 2 & 13 \\
\hline $21-30$ & 6 & 20 \\
\hline $31-50$ & 2 & 10 \\
\hline$\geq 51$ & 0 & 50 \\
\hline Sem Informação & 58 & 0 \\
\hline
\end{tabular}

1' valores da coluna representam a área avaliada com suspeita de resistência em hectares; ${ }^{2 /}$ valores da coluna representam o percentual de produtores do Estado do Paraná que possuem área nas dimensões descritas na coluna $1 ;{ }^{3 /}$ valores da coluna representam o percentual de produtores do Estado do Rio Grande do Sul que possuem áreas nas dimensões descritas na coluna 1 .

Tabela 3 - Tempo de permanência no sistema de semeadura direta nos Estados do Paraná e Rio Grande do Sul

\begin{tabular}{|c|c|c|}
\hline \multirow{2}{*}{$\begin{array}{c}\text { Período }^{\mathbf{1}^{\prime}} \\
\text { (anos) }\end{array}$} & \multicolumn{2}{|c|}{ Estado } \\
\cline { 2 - 3 } & $\mathrm{PR}^{2 /}$ & $\mathrm{RS}^{3 /}$ \\
\hline$\leq 4$ & 23 & 10 \\
\hline $5-8$ & 37 & 67 \\
\hline$>8$ & 40 & 23 \\
\hline
\end{tabular}

1/ valores na coluna representam o período de tempo (anos) de implantação do sistema de semeadura direta nas propriedades amostradas; 2! valores da coluna representam a porcentagem de propriedades amostradas que utilizam o sistema de semeadura direta relacionadas ao período de implantação do sistema no Estado do Paraná; ${ }^{3 /}$ valores da coluna representam a porcentagem de propriedades amostradas que utilizam o sistema de semeadura direta relacionadas ao período de implantação do sistema no Estado do Rio Grande do Sul.

A maioria das propriedades ( $>74 \%)$ amostradas foi cultivada com soja por vários anos sucessivamente. Várias são as alternativas de rotação de mecanismos de ação de herbicidas para o controle de Bidens spp. na cultura de soja, podendo ser citados os seguintes mecanismos: inibidores da ALS, inibidores de 
PROTOX, inibidores de HPPD, inibidores de FS II e inibidores de EPSPs (Vidal \& Merotto Jr., 2001). Em 95\% das lavouras de soja amostradas do Paraná e em 100\% daquelas lavouras de soja amostradas no Rio Grande do Sul utilizavam-se apenas herbicidas inibidores da ALS no controle de plantas daninhas dicotiledôneas há mais de dois anos.

Esse resultado contrasta com o encontrado no levantamento das práticas agronômicas associadas à seleção de Euphorbia heterophylla resistente aos inibidores da ALS, que detectou aumento do uso de inibidores de PROTOX ou de sua mistura com inibidores da ALS (Vidal et al., 2004). O uso contínuo de herbicidas de mesmo mecanismo de ação provavelmente exerceu elevada pressão de seleção e deve ter selecionado biótipos resistentes a esses herbicidas. Outro fator que possivelmente deve ter favorecido a seleção de biótipos resistentes é a elevada freqüência inicial do gene de insensibilidade aos inibidores da ALS. Simulações matemáticas demonstram que, em apenas um ano de utilização dos herbicidas inibidores da ALS numa área de um hectare e com população de Bidens spp. de 10 plantas $\mathrm{m}^{-2}$, a probabilidade de selecionar uma planta daninha resistente é de 85\% (Vidal \& Anjos, 2003).

Para se evitar ou reduzir o surgimento de plantas resistentes aos herbicidas, é necessário que ocorram algumas modificações nas práticas agrícolas utilizadas atualmente. Uma das alternativas para prevenir e manejar a resistência é utilizar racionalmente os herbicidas e, também, usar rotação de produtos que possuam diferentes mecanismos de ação, o que diminuirá a pressão de seleção exercida por estes (Gressel \& Segel, 1990; Winkler et al., 2003).

Quanto ao maquinário utilizado, 50\% dos produtores das áreas amostradas no Paraná e $100 \%$ dos produtores do Rio Grande do Sul afirmaram que possuem colhedora própria. Além disso, 37\% dos produtores do Paraná e $74 \%$ dos produtores do Rio Grande do Sul não alugavam máquinas para vizinhos. Como essa é uma prática que difere entre os dois Estados, seria importante avaliar se há diferenças na similaridade genética dos biótipos amostrados nos dois Estados, de forma que isso seria um indicador de possivel dispersão da resistência através da distribuição de sementes por máquinas agrícolas.
Quando questionados sobre o conhecimento do problema de resistência de plantas daninhas na propriedade dos vizinhos, $44 \%$ dos produtores do Paraná e $80 \%$ dos produtores do Rio Grande do Sul responderam afirmativamente, indicando que a resistência se encontrava amplamente distribuída em ambos os Estados.

Este trabalho demonstrou que biótipos de Bidens spp. resistentes aos herbicidas inibidores da ALS estão amplamente distribuídos no Paraná e Rio Grande do Sul. As informações fornecidas pelos agricultores permitem afirmar que o uso continuado e intenso de herbicidas inibidores da ALS nas lavouras de soja foi um importante fator que favoreceu a seleção de indivíduos resistentes. Como enfatizado por Vidal et al. (2004), há necessidade de conscientizar agricultores e legisladores quanto à necessidade de rotação e principalmente de misturas de herbicidas pertencentes a mecanismos de ação diferentes, de forma que essas técnicas possam ser empregadas na prevenção à resistência de plantas daninhas.

\section{AGRADECIMENTOS}

À CAPES, CNPq e FAPERGS, pelo apoio aos pesquisadores e ao projeto.

\section{LITERATURA CITADA}

AHRENS, W. H. (Ed.) Herbicide handbook. 7.ed. Champaign: Weed Science Society of America, 1994. 352 p.

BOURGEOIS, L.; MORRISON, I. N. A survey of ACCase inhibitor resistant wild oat in high risk township in

Manitoba. Can. J. Plant Sci., v. 77, n. 4, p. 703-708, 1997.

BROWN, T. M. Molecular genetics and evolution of pesticide resistance. Washington: ACS, 1996. $340 \mathrm{p}$.

COSTA, J. A. Cultura da soja. Porto Alegre: Evangraf, 1996. $233 \mathrm{p}$.

DEVINE, M.; DUKE, S. O.; FEDTKE, C. Physiology of herbicide action. Englewood Cliffs: PTR Prentice Hall, 1993. $441 \mathrm{p}$.

GRESSEL, J.; SEGEL, L. A. Modeling the effectiveness of herbicides rotation and mixtures strategies to delay or preclude resistance. Weed Technol., v. 4, n. 1, p. 186-198, 1990.

Planta Daninha, Viçosa-MG, v. 23, n. 4, p. 677-682, 2005 
HESS, F. D. Light-dependent herbicides: na overview.

Weed Sci., v. 48, n. 2, p. 160-170, 2000.

MONQUEIRO, P. A.; CHRISTOFFOLETI, P. J.; DIAS, C. T. S. Resistência de plantas daninhas aos herbicidas inibidores da ALS na cultura da soja. Planta Daninha, v. 18, n. 3 , p. $419-425,2000$.

OWEN, M. D. K. World maize/soybean herbicide resistance. In: POWLES, S. B.; SHANER, D. L. Herbicide resistance and world grains. Boca Raton: CRC Press, 2001. p. 101-164.

PRESTON, C.; POWLES, S. B. Evolution of herbicide resistance in weeds: initial frequency of target site-based resistance to acetolactate synthase-inhibiting herbicides in Lolium rigidum. Heredity, v. 88, n. 1, p. 8-13, 2002.

RADOSEVICH, S.; HOLT, J.; GHERSA, C. Weed ecology: implications for management. New York: John Wiley \& Sons, 1997. 589 p.
VIDAL, R. A.; ANJOS, A. Calpre 1.0: Programa de computador para cálculo de probabilidade da resistência aos herbicidas. In: REUNIÃO DE PESQUISA DE SOJA DA REGIÃO SUL, 2003, Porto Alegre. Resumos... Porto Alegre: 2003. p. 196.

VIDAL, R. A.; FLECK, N. G. Análise de risco da ocorrência de biótipos de plantas daninhas resistentes aos herbicidas. Planta Daninha, v. 15, n. 2, p. 152-161, 1997.

VIDAL, R. A.; MEROTTO JR., A. Herbicidologia. Porto Alegre: Evangraf, 2001. 152 p.

VIDAL, R. A. et al. A field survey of crop management practices and distribution of ALS resistant Euphorbia heterophylla in two states in southern Brazil. Planta Daninha, v. 22, n. 3, p. 403-410, 2004.

WINKLER, L. M.; VIDAL, R. A.; BARBOSA NETO, J. F. Caracterização genética de Euphorbia heterophylla resistente a herbicidas inibidores da acetolactato sintase. Pesq. Agropec. Bras., v. 38, n. 9, p. 1067-1072, 2003. 